\title{
Elevated Test Result
}

National Cancer Institute

\section{Source}

National Cancer Institute. Elevated Test Result. NCI Thesaurus. Code C81326.

A result of a test that is higher than a previous value or a normal range of values. 